\title{
Green transportation system to promote sustainable lifestyle in Chulalongkorn University
}

\author{
Jirarat Pinthong ${ }^{1}$, Korb Limsuwan ${ }^{1}$, and Boonchai Stitmannaithum ${ }^{2, *}$ \\ ${ }^{1}$ Energy and Environment Unit, Office of Physical Resources Management, Chulalongkorn University, Thailand \\ ${ }^{2}$ Office of the University, Chulalongkorn University, Thailand
}

\begin{abstract}
Chulalongkorn University $(\mathrm{CU})$ is located at the heart of Bangkok, which is one of the most traffic congested cities in the world. It is very crucial for the university to develop a green and clean transportation system that is good for both the CU community and the whole society. To reduce on-campus traffic, the university provides four parking buildings on the edge of four corners of the campus to serve visitors, students, faculties and staffs who travel by private cars. While providing added convenience, these parking garages reduce traffic congestion on campus and, thus, pollutions from harmful emissions and traffic noises. To promote eco-friendly transportation in the campus, the university provides "CU Shuttle Bus" - an electric shuttle bus service that cover not only campus area, but also reach out to public sky train and subway stations around the campus. The CU Shuttle Bus's mobile application, developed by engineering students, helps improve user experience by showing all useful information including campus map, bus routing, and real-time locations of all buses. To encourage walking and cycling within the campus and to promote good health and fitness, the university has been constructing covered walkways and bike lanes throughout the campus. In addition, "CU Bike" - a bike sharing program, was first introduced in 2014 and has quickly grown in popularity among CU students since. A new "CU Toyota Hamo", an electric vehicle rental program, is another great option of green transportations for those who cannot ride a bicycle and for older people of the aging society. All these projects help promote the development of innovations and practices that are both sustainable and protective of the environment of Chulalongkorn University, as well as the surrounding community, the country and planet as a whole.
\end{abstract}

\section{Introduction}

Transportation is a big part of everyday life. Commute eco-friendly is the best way to show our responsibility to the environment and society. Bangkok city suffers tremendously from the traffic congestion and air pollution [1-2]. Located at the center of Bangkok, Chulalongkorn University (CU) is right at the heart of the problem area. Therefore, a green transportation system is a very important part of the CU $100^{\text {th }}$ Anniversary University Development Plan [3]. The goals of the university master plan are to reduce on-campus traffic and air pollution together with promoting eco-friendly transportation among CU community.

CU "Green University" policy was implemented in 2004 to improve physical environment and facility of the university to be more eco-friendly. In 2008, CU had set a new goal to become a "Sustainable University". The policy focuses mainly on cultivating mind set and concern about environment and sustainability. This way $\mathrm{CU}$ students can become role models and drive a whole society toward sustainability. It is very important that the university takes action to set an example and to inspire both students and the rest of the society.

\section{Parking system}

Chulalongkorn University has implemented "Green University" policies to limit the number of vehicles that enter and park on campus as well as to provide shuttle transport within the grounds and promote walking and riding bicycles. To encourage green transportation, the university started the university parking building project (Fig. 1), because the number of faculties, staffs and students, who drive to the university have significantly increased in recent years. This has led to problems on campus, such as noise and air pollution, traffic congestion and a lack of parking spaces. To solve those problems following the university development plan, the parking buildings have been constructed at the four corners of the campus to achieve the following: (i) reduce vehicle traffic within the campus, (ii) reduce $\mathrm{CO}_{2}$ emission and air pollution inside the campus area, (iii) reduce noise pollution from on-campus traffic, and (iv) provide sufficient parking spaces for those who still need to travel using private cars. People can commute from each parking building to various campus locations as well as popular attractions around the university by walking, cycling or the free shuttle bus service. The car park building has solved the lack of parking spaces and has also reduced traffic on campus. Not only do they enhance the

\footnotetext{
Corresponding author: boonchai.s@chula.ac.th
} 
campus atmosphere, they make the university a safer place for people living inside and around the campus.

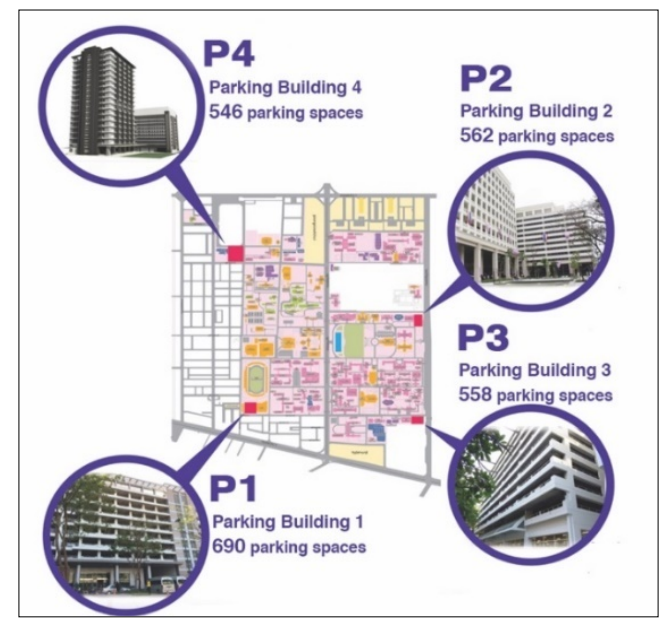

Fig. 1. Parking buildings on four corners of the campus

\section{Mass transportation}

As located at a city center, the university encourages $\mathrm{CU}$ students and staffs to use public transportation to help reduce the traffic problem of the city as well as the campus. To serve the community, there is "CU Shuttle Bus" that provides a free shuttle service for the $\mathrm{CU}$ community and visitors (Fig. 2). The 26 fully- electric buses are operated on 6 routes that not only cover all campus area but also reach out to connect with the public transportation systems of the city. People using the Bangkok Mass Transit System (BTS) skytrain can take the shuttles on route no.1, no. 2 and no. 4 getting into the campus. While people using the Metropolitan Rapid Transit (MRT) subway can get to a hub of the CU Shuttle Bus within a several minute's walk.

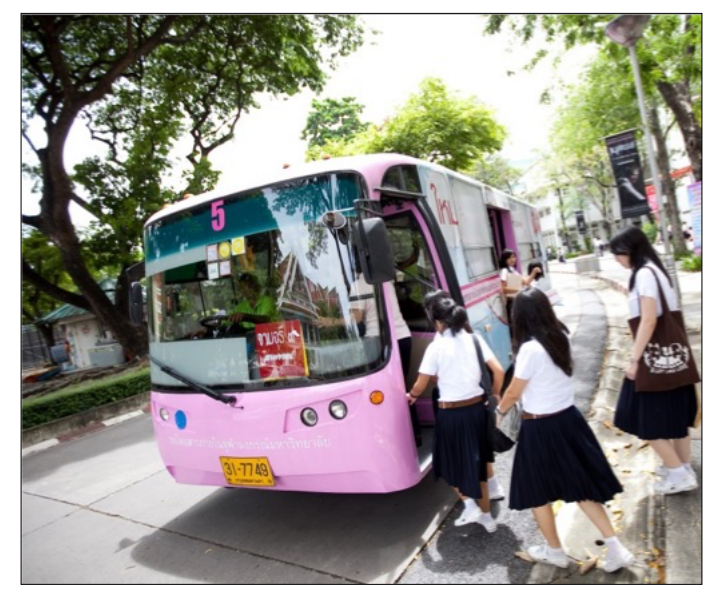

Fig. 2. CU Shuttle Bus

Integrating Information Technology to improve a service, the CU Shuttle Bus mobile application has been developed by a group of engineering students and available for free-download online for both Android and iOS mobile devices. The application provides all useful information to assist all shuttle users including university map, shuttle bus station and routing, real-time location of buses. For young generation like CU students, a social media such as Facebook is used to promote mass transportation on campus and receive feedback from all passengers to keep improving the service that both serves CU community and is safe for our environment.

\section{Walking and biking in campus}

To cultivate sustainable lifestyle among CU community, the university has promoted walking and cycling within the campus as the greenest mode of transportation. Both walking and biking are not only super clean for the environment, but also beneficial for a good health and wellbeing of individuals. To encourage cycling, the university provides bicycle lanes and parking racks throughout the campus ground. Since 2010, over a thousand of bicycles have been distributed to each and every units of the university for staffs to commute within the campus. Most of those bicycles were sponsored by Metropolitan Electricity Authority as a corporate social responsibility project with the following objectives: (i) reduce carbon monoxide emission from vehicles which is a major cause to global warming and air pollution, (ii) promote exercise via cycling, (iii) reduce vehicle traffic within and around campus, and (iv) promote efficient use of energy. For campaigning, there is an annual event led by the president of the university to promote cycling in campus (Fig. 3).

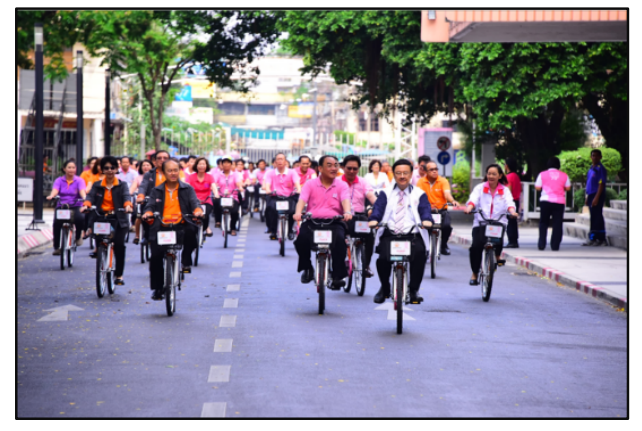

Fig. 3. The annual event to promote cycling in campus

In 2014, "CU Bike", a bike sharing program was implemented on campus with 5 stations and 120 bicycles made available (Fig. 4). The CU Bike is very eco-friendly. Paddling a bike simultaneously generate electricity and store within a battery to supply a lighting system, a GPS system and a control panel of the bike. The solar panels also a renewable-energy source for a communication system at the bike stations. In addition, the bike has a chain guard and front storage which make it very practical and user-friendly. As a result, this sharing bike program has grown in popularity among CU students with average of over 77,000 rental each year. In 2016, three additional CU Bike stations has been constructed to expand the service. 


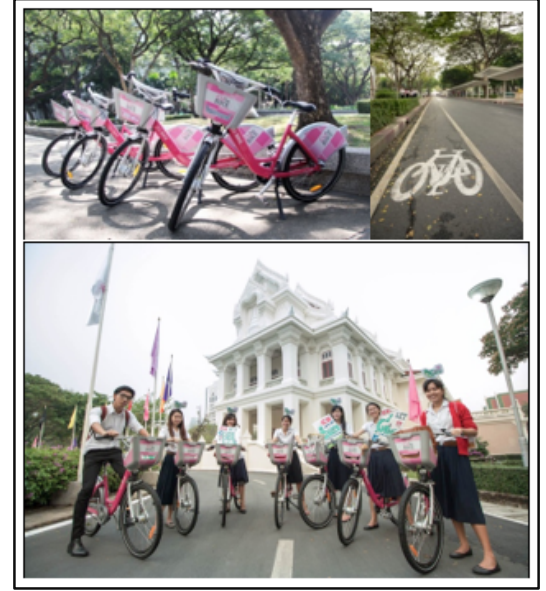

Fig. 4. CU Bike

\section{Electric vehicle (EV)}

"CU Toyota Hamo" is a collaborative project between Chulalongkorn University and Toyota Motor Thailand with an objective to initiate the first EV-sharing system in Thailand. "Hamo" stands for "Harmonious Mobility Network" which is an innovation for compact EV-sharing system connecting and integrating personal mobility with public mass transit networks (Fig. 5).

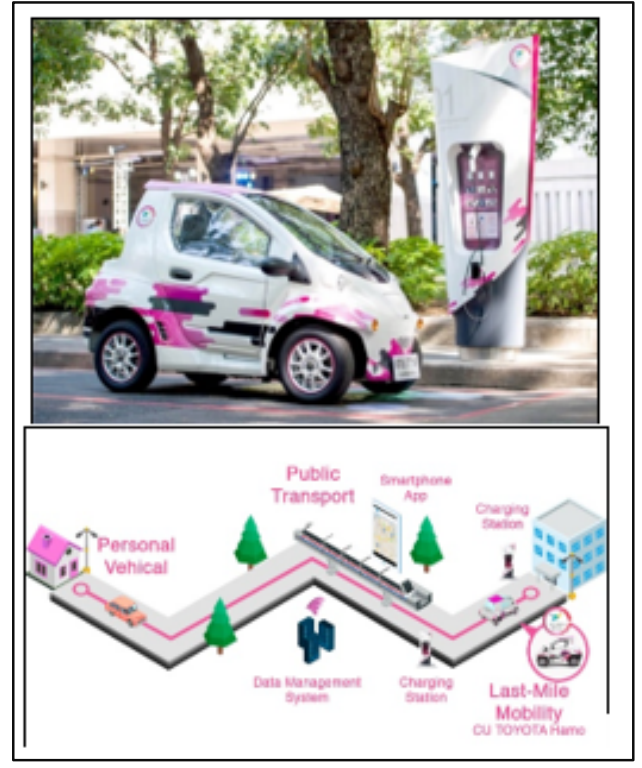

Fig. 5. CU Toyota Hamo

Thailand is currently facing various mobility issues. Quality of life is also negatively affected by the mobility issues. EV-sharing is a new option which connects public transportation system to destinations. Moreover, it increases economic value (sharing economy), reduces pollution, and helps people to drive when necessary.

$\mathrm{CU}$ Toyota Hamo is another great option of green transportations for those who cannot ride a bicycle and for older people of the aging society. At the same time, it supports a sustainable society and promotes a sustainable lifestyle in the university.

\section{Concluding remarks}

In conclusion, $\mathrm{CU}$ promotes green transportation and sustainable lifestyle on campus via CU Bike, CU Shuttle Bus, CU Toyota Hamo service, along with parking facilities and covered walkways. Implementing clean and green transportation system on campus encourages both $\mathrm{CU}$ community and visitors to cultivate their personal habits of commuting with responsibility. As a result, nowadays, the on-campus traffic has been significantly reduced and the air quality has become much cleaner and healthier.

Chulalongkorn University has initiated many projects and activities to achieve its goal of becoming a Green and Sustainable University that not only provides a very best environment for university life, but also inspires students to take a responsibility in driving our society together toward sustainability.

\section{References}

1. INRIX. INRIX Global Traffic Scorecard. Available online at http://inrix.com/scorecard/, accessed on 2018, February 2. (2017)

2. The Nation. Bangkok air pollution remains at harmful level. Available online at http://www.nationmultimedia.com/detail/national/30 338660, accessed on 2018, February 2. (2018)

3. Chulalongkorn University, Faculty of Architecture and Faculty of Engineering, Report of Chulalongkorn University's 100-year Anniversary Development Plan. Chulalongkorn University. (2000) 